\title{
DE LA FIEBRE AMARILLA A LA COVID-19:
}

\section{DOS SIGLOS DE EPIDEMIAS Y PANDEMIAS EN MÉXICO*}

\author{
FROM YELLOW FEVER \\ TO COVID-19: \\ TWO CENTURIES OF EPIDEMICS \\ AND PANDEMICS IN MEXICO
}

\author{
Ana María Carrillo \\ UNAM-Facultad de Medicina \\ farga@unam.mx
}

\begin{abstract}
This paper focuses on the way in which societies reacted to epidemics, endemics, and pandemics in Mexico from 1821 to 2021. It shows that despite the separation of time and the differences characterizing the affected societies, the population's reactions to these disease outbreaks have been largely similar. However, there have also been deep dissimilarities between them, which have depended on the way in which health and disease have been understood in a given time and by given groups, as well as on the population's vulnerability in the face of such calamities.
\end{abstract}

Keywords: Mexico, epidemics, endemics, pandemics, 19th and 20th centuries.

\section{Resumen}

Este artículo presta atención a la manera en que las sociedades han reaccionado ante epidemias, endemias y pandemias en México, de 1821 a 2021. Trata de mostrar que, a pesar del tiempo que las separa y las diferencias de las sociedades a las que han afectado, las reacciones de la población ante ellas han tenido grandes similitudes, si bien ha habido también desemejanzas profundas entre ellas, las cuales han dependido de la manera en que la salud y la enfermedad han sido concebidas en determinada época y por determinados grupos, y de la vulnerabilidad de la población ante estos flagelos.

Palabras clave: México, epidemias, endemias, pandemias, siglos XIX y XX.

*Agradezco la lectura cuidadosa y las acertadas sugerencias de dos revisores(as) anónimos(as), que permitieron mejorar la versión original de este trabajo. 


\section{Introducción}

Cuando el 11 de marzo de 2020 la Organización Mundial de la Salud declaró que la epidemia de COVID-19 (por su acrónimo en inglés: coronavirus disease y el año del primer caso reportado) era ya una pandemia, las reacciones de los pobladores del mundo oscilaron entre la incredulidad y el miedo. A pesar de que había predicciones sobre una posible pandemia de grandes dimensiones por virus emergentes, Occidente -con sus vacunas, antibióticos y desarrollo tecnológico- se sentía libre de ellas.

Cierto es que desde que el primer caso del síndrome de inmunodeficiencia adquirida fue descrito en 1981, la pandemia de $\mathrm{VIH} /$ Sida significó un golpe a la idea de que los países desarrollados habían conquistado las enfermedades infecciosas; hasta hoy, ésta ha sido responsable de 70 millones de infectados y casi 33 millones de muertos (UNAIDS, 2020). Sin embargo, por un lado, las ciencias médicas han hecho progresos en el diagnóstico y tratamiento de la enfermedad; y, por otro, en los países occidentales la pandemia ha afectado en mayor medida a los hombres trabajadores sexuales, los hombres que tienen sexo con hombres, las mujeres trans y las personas que se inyectan drogas, y quienes no están en esos grupos se sienten menos vulnerables.

También es cierto que en las últimas décadas del siglo XX y las primeras del XXI la humanidad había vivido otras pandemias. Por ejemplo, la séptima pandemia de cólera comenzó en 1960 en Indonesia, llegó a América a principios de 1991 y se ha vuelto endémica en algunos países (Ryan, 2011). Pero muchos la ven como lejana, pues este padecimiento se transmite por agua $o$ alimentos contaminados y afecta a las poblaciones marginadas que carecen de agua potable y drenaje.

De la enfermedad por el virus del ébola, identificada por vez primera en 1976, hubo una epidemia en 2014, que es considerada la epidemia viral hemorrágica más grande de la historia; $40 \%$ de las personas que contrajeron la enfermedad fallecieron. Sin embargo, la enfermedad no se convirtió en pandemia, ya que se limitó a África Occidental (Gostin, Lucey y Phelan, 2014).

Antes de la COVID-19 privaba la idea de que una pandemia que pudiera extenderse a todos los países y, dentro de ellos, a todas las clases sociales, pertenecía al pasado; sin embargo, esta enfermedad golpea hoy a gran escala a la tierra. Hasta el 9 de abril de 2021 se habían reportado 134,548,724 casos de la enfermedad y 2,915,432 muertes a causa de ella (Worldometer, 2021). Aunque las pandemias han sido comunes en la historia de la humanidad, la enfermedad del coronavirus-19 es una situación extraordinaria en nuestras vidas, y ha despertado gran interés entre académicos, tomadores de decisiones y público en general por el pasado de las pandemias, y es que la historia ayuda a poner las cosas en perspectiva.

La población mexicana, como la de cualquier otro país, ha estado expuesta de manera constante a la muerte provocada por endemias, epidemias y pandemias. Los términos con que se denomina a los problemas colectivos de salud han variado con el paso del tiempo. Hoy se define a la endemia como la presencia habitual de una enfermedad, transmisible o no transmisible, en una determinada zona geográfica o un grupo de población, en donde persiste de forma continuada; fue, por centurias, el caso del paludismo.

Epidemia, en cambio, se refiere a las enfermedades que visitan a la comunidad. Originalmente, se hablaba de epidemia cuando una enfermedad contagiosa se propagaba rápidamente en una población determinada, y afectaba a un gran número de personas durante un periodo de tiempo concreto; por ejemplo, una epidemia de tosferina. Pero en la actualidad, se aplica también a las enfermedades crónicas cuando un gran número de personas las padecen; la Organización Mundial de la Salud considera que hay epidemias mundiales de cardiopatías o de cáncer.

Por último, pandemia es una enfermedad que afecta a áreas geográficamente extensas, y tiene un alto grado de infectividad y 
un fácil traslado de un sector geográfico a otro. Actualmente, para considerarla como tal debe afectar al menos a dos continentes. El cólera fue quizá la pandemia más representativa del siglo XIX, como la influenza, la poliomielitis y el Sida lo fueron del siglo $X X$ y la COVID-19 lo es en el XXI.

A veces no es fácil distinguir los límites entre unas y otras. La viruela fue, en el siglo XVI, una pandemia que provocó una catástrofe demográfica en América, pero luego se volvió endémica y cada cierto número de años era causa de epidemias (Bustamante, 1977). Fue, también, el caso de la fiebre amarilla, que era endémica en Veracruz, pero tenía exacerbaciones epidémicas en ciertos meses del año. Y algunos epidemiólogos pronostican que algo similar pasará con la COVID-19.

Epidemias, endemias y pandemias han sido importantes no sólo por el número de defunciones que han causado sino también por su significación social (González, 1970). Por investigaciones paleopatológicas, sabemos de la existencia de enfermedades entre los antiguos pobladores de México (Serrano y Castillo, 1984), y crónicas y códices revelan la presencia de epidemias en el México prehispánico (Hernández, 1962). Se estudia cada vez más el impacto que tuvieron las enfermedades infectocontagiosas en el momento de la conquista militar del Imperio español en el siglo XVI (Cook y Borah, 1977; McCaa, 1995) y, después, durante toda la época coIonial (Cooper, 1980; Molina del Villar, 1996), incluyendo la guerra de Independencia (Márquez, 1994; González Flores, 2017). ${ }^{1}$

Este artículo se ocupa, de manera general, de algunas epidemias, endemias y pandemias ocurridas en México desde el fin de la guerra de Independencia hasta 2021, prestando atención a la manera en que las sociedades reaccionaron ante esas muertes colectivas. Intenta mostrar que hay paralelismos entre los daños causados por las epidemias

1 Éstos son sólo algunos ejemplos de estudios sobre el tema, y lo mismo puede decirse para el resto de las epidemias referidas en el presente artículo. Sobre epidemias en general, véanse los trabajos contenidos en: Florescano y Malvido (1982) y en Molina del Villar et al. (2013). del pasado y la que hoy vivimos, lo mismo que continuidades en la forma de reaccionar ante estas emergencias sanitarias, a pesar de los siglos que las separan y las diferencias de las sociedades a las que han afectado. Pero, por supuesto, hay también desemejanzas profundas entre ésta y aquéllas.

Todavía resulta difícil penetrar en el sufrimiento causado en la población por algunas epidemias del pasado, para las que la medicina tenía más preguntas que respuestas, pues representaban catástrofes demográficas que dislocaban la sociedad toda, y durante las cuales las ciudades o pueblos eran acordonados, momento a partir del cual se impedía la salida de seres humanos y objetos, y los muertos eran enterrados de manera anónima, en enormes fosas colectivas. Las diferencias han dependido de la manera en que la salud y la enfermedad han sido concebidas en cada época y por determinados grupos, en consonancia con los contextos religiosos, políticos, sociales y culturales en que se presentan, y han dependido, igualmente, de la violencia de tales flagelos y de la vulnerabilidad de la población ante ellos.

\section{Siglo XIX: tiempo de incertezas}

\section{Perfil epidemiológico}

Los problemas colectivos de salud han sido inevitables en la vida de los mexicanos. Apenas unos días después del 27 de septiembre de 1821, fecha en que, tras 11 años de guerra entre insurgentes y realistas, fue expedida el Acta de Independencia que declaraba la soberanía de la nación, hubo una epidemia de fiebre amarilla en Altamira, hoy Tamaulipas, que llegó luego a Tampico; se atribuyó a un navío que había llegado de La Habana, y causó 1500 muertes. Pasarían ocho décadas antes de que se aceptara la teoría del cubano Carlos Finlay de que la enfermedad es trasmitida de un sujeto enfermo a uno sano por el mosquito Aedes aegypti, y aún más tiempo antes de que fuera identificado el agente que la causa: el virus de la fiebre amarilla (Bustamante, 1958). 
Desde entonces, endemias, epidemias y pandemias se sucedieron una tras otra. En su Historia de la salubridad y de la asistencia en México, Álvarez Amézquita et al. (1960) hicieron un recuento de ellas en la historia del territorio que hoy es México: viruela, sarampión, escarlatina, tosferina, fiebre amarilla, paludismo, mal de pinto, tifus, cólera, influenza, lepra, tuberculosis y sífilis fueron constantes en el perfil epidemiológico del siglo XIX.

La inestabilidad política del México decimonónico fue clave en la presencia de la enfermedad en sus formas colectivas. Al menos desde la guerra del Peloponeso (Littman y Littman, 1969), ocurrida en el siglo $\mathrm{V}$ antes de nuestra era, hay constancia de que los conflictos armados favorecen la expansión de las enfermedades epidémicas, con su movimiento de tropas, desplazamiento de personas, abandono de los trabajos del campo, extensión del hambre, agudización de la pobreza y descuido de los trabajos sanitarios. Y en el periodo de la historia de México que va de 1821 a 1876 hubo mucha violencia: el intento de reconquista por parte de España, guerra con Francia (ganada por ese país), guerra con Estados Unidos (en la que México perdió la mitad del territorio nacional), intervención francesa, lucha continua entre conservadores y liberales y rebeliones indígenas. Si la viruela llegó en el siglo XVI con los conquistadores, la difteria fue introducida al país por las tropas de Napoleón durante la Intervención francesa (Lobato citado por Álvarez Amézquita et al., 1960).

Los límites del conocimiento científico contribuyeron también a la permanencia de endemias y epidemias. Como señaló el salubrista e historiador Miguel E. Bustamante (1982), en el siglo XIX poco podía hacerse ante la devastación causada por tantas muertes simultáneas, porque a nivel mundial había desconocimiento de las formas clínicas de las enfermedades dominantes y de sus causas, además de ignorancia respecto de su modo de transmisión, tratamientos efectivos o medidas de prevención.

Las endemias de tuberculosis, sífilis y le- pra han afectado a todos los lugares de la república; pero otras han estado relacionadas con ciertos ambientes geográficos: tifus en las alturas, fiebre amarilla en las costas, paludismo en las regiones de clima tropical, mal de pinto en la cuenca del río Balsas, bocio en las vertientes, oncocercosis en tierras altas y húmedas y con presencia de ríos rápidos, aunque en el siglo XIX las ciencias médicas aún no podían explicar por qué. El carácter endémico de algunos padecimientos hacía que la gente se acostumbrara a ellos; en cambio, las enfermedades epidémicas, a pesar de su frecuencia, solían tomar a las poblaciones por sorpresa (Peset y Peset, 1972), ya que atacaban repentinamente a grandes grupos y podían acabar con millares de vidas humanas en poco tiempo.

\section{La epidemia de tifus de 1892-1893}

Una epidemia de tifus, que en México era conocido como tifo, afectó al centronorte de México a inicios de la última década del siglo XIX: Aguascalientes, Hidalgo, Querétaro, estado de México, Guanajuato, Michoacán, Puebla, San Luis Potosí, Zacatecas y la ciudad de México (Gámez, 1999). Tomo aquí, como ejemplo, la epidemia de Guanajuato, en un intento de acercamiento a los sentimientos y reacciones de personas de pasadas centurias.

En Guanajuato, el tifo era endémico durante el verano y solía hacerse epidémico en el invierno. Durante los últimos meses de 1892 y los primeros de 1893 hubo una epidemia que tuvo una alta letalidad (proporción de personas que mueren por una enfermedad entre los afectados por la misma en un periodo y área determinados). Parecía que la enfermedad asaltaba por tandas: a veces morían sobre todo los hombres; otras veces, casi sólo mujeres; unas más, principalmente niños. Si había enfermos en la familia, no perdonaba ni a los niños de pecho, aunque quien los criaba estuviera sana. Se dejaba de ver a una persona y en unos cuantos días circulaba como cierta la noticia de su muerte. En cuanto alguien se sentía enfermo, perdía la esperanza de alivio y se disponía a morir. 
La epidemia afectó a las personas conocidas y provocó una gran emigración: puntos tan habitados como la Plaza Mayor se quedaron casi solos; todas las familias acomodadas y de medianos recursos se fueron. La población estaba amedrentada. Al toque de la campana mayor de la parroquia, se encendían fogatas en calles y plazas para desinfectar con azufre los caños que daban al río y, de esta forma, combatir la corrupción del ambiente. De las casas salían personas en agonía que sucumbían pocos instantes después, y había por todos lados cadáveres hacinados en carretones que eran inhumados anónimamente. Muy raro era encontrar gente que no vistiera de luto; las conversaciones de todos giraban en torno del mal y los conocidos se saludaban preguntando: “¿Quién ha muerto?”.

Muchos se negaban a ver a un médico porque estaban convencidos que hacerlo aseguraría su deceso. Algunos médicos y sacerdotes tenían el cuidado de anotar el número de enfermos que habían atendido, lo mismo que el de fallecidos; pero sus datos no coincidían con los del Registro Civil, ya que casi todos los pobladores trataban de ocultar su enfermedad a las autoridades. Causaba indignación que la policía se presentara en la casa en que acababa de fallecer un enfermo de tifo y sacara el cadáver del que había sido hermano, padre, hijo. Algunas familias desaparecieron: sus muebles fueron quemados en el cerro, y sus casas, lavadas con creolina.

Aunque el gobierno no ordenó la clausura de los templos, como algunos le suplicaban, sí mandó cerrar los colegios. En abril mejoró la situación, pero entonces fue visto un sinnúmero de mariposas naranjas con listas negras, lo que aterrorizó a los pobladores que lo consideraron un símbolo premonitorio de que sus males aún no habían terminado (Armendáriz, 1894). ${ }^{2}$

\footnotetext{
2 El relato de esta epidemia está basado, sobre todo, en el trabajo de Armendáriz; también en el Periódico Oficial del Gobierno del Estado de Guanajuato, publicado durante el tiempo de la epidemia, y en los artículos de prensa: "El tifo", La Patria, 5 de enero de 1893, p. 3; "Noticias menudas", La Voz de Guanajuato, 8 de enero de 1893, p. 3; "Muy peligroso", La Patria, 26 de enero de 1893, p. 3; "Medida higiénica", La Patria,
}

\section{Las pandemias: el caso del cólera, 1833}

Si las epidemias eran motivo de angustia, las pandemias provocaban terror; éstas eran anunciadas porque iban recorriendo el mundo, a veces a lo largo de años, y eran responsables de gran número de enfermos y muertos. De las pandemias que sufrieron los habitantes de México en el siglo XIX, quizá las más dramáticas fueron las de cólera (Contreras Sánchez y Alcalá Ferráez, 2014), que golpearon al mundo en cinco ocasiones: 1817-1823, 1826-1837, 1840-1859, 1863-1875 y 1881-1896.

De acuerdo con Louis Chevalier (2018) y Asa Briggs (1961), el cólera fue un ejemplo de padecimiento creado por la industrialización, con la extensión del comercio y el desarrollo del transporte, y afectó principalmente a ciudades donde había un rápido proceso de urbanización e insalubridad en las habitaciones y lugares de trabajo de gran parte de la población. Médicos, caricaturistas, periodistas y gente común dejaron testimonios que muestran el sentir de las personas, y a partir de los cuales los historiadores escribimos nuestras historias.

La primera pandemia murió en los confines del Imperio ruso, pero la segunda llegó a Europa y América, y fue la más fatal (Márquez, 1994). En ese tiempo no se conocía la causa de la enfermedad (la bacteria Vibrio cholerae) que producía diarrea y vómito incontrolables, ni había cura para ella, y quienes la padecían podían deshidratarse y fallecer en pocas horas. Los americanos esperaban que el mar la pudiera detener: no fue así. La enfermedad se embarcó hacia América con los inmigrantes irlandeses. Algunos iban en busca de trabajo, otros huyendo de persecuciones religiosas o -irónicamentedel cólera.

Tratando de evitar su llegada, en México

1 de febrero de 1893, p. 3; "El tifo en Guanajuato", La Voz de México, 1 de febrero de 1893, p. 3; "Noticias alarmantes del tifo en Guanajuato", El Universal, 18 de febrero de 1893, p. 2; "Sensibles defunciones", La Voz de Guanajuato, 19 de febrero de 1893, p. 2; "Buena medida", La Voz de Guanajuato, 19 de febrero de 1893, p. 2; "Purísima del Rincón", El Siglo Diez y Nueve, 28 de febrero de 1893, p. 3. 
se publicó un bando que obligaba a hospitales, conventos, iglesias, así como a vecinos, dueños de vinaterías, cafeterías y jacalones de pulquerías, a barrer las calles y llevar la basura a atarjeas para la banqueta, mientras que las cortadurías y tocinerías deberían depositar sus desechos en muladares. Los dueños de casas de matanza no podían dejar correr inmundicias por caños sino tirarlos diariamente; lo mismo aplicaba para los panaderos y fruteros. Los caseros o dueños de posadas tenían que encargarse de los baños o lavaderos públicos ("Bando del 15 de marzo de 1833"). Pero el cólera morbus iba a burlarse de las precauciones de los hombres. A México, el cólera arribó por vez primera en 1833, por la frontera norte (Cuenya Mateos et al., 1992). En Tampico, una ciudad de 3000 habitantes, murieron 900 en 17 días, y un buque francés en ese puerto perdió a toda su tripulación, excepto a un hombre (Chambers, 1938). De ahí, la enfermedad pasó a casi todos los estados de la república mexicana.

Las epidemias y pandemias son cosa de todos; no obstante, históricamente se les ha tratado de ver como asunto de los otros, a los que se ha culpado de la situación. Cuando el cólera llegó a México, una naciente burguesía, encabezada por el vicepresidente Valentín Gómez Farías, había emprendido radicales reformas a la organización política y social, que limitaban los privilegios del clero y del ejército, y contra las que éstos se rebelaron al grito de "iReligión y fueros!". El pueblo aseguraba que los rebeldes envenenaban las aguas, aunque, en realidad, enfermaban de cólera tanto éstos como las tropas leales al gobierno (Hutchinson, 1984). Francisco Pablo Vázquez, obispo de Puebla, quien había prohibido, so pena de excomunión, el Emilio de Rousseau y las obras de Voltaire, publicó una carta pastoral en la que aseguraba que la enfermedad era un castigo decretado por la divinidad, a causa del desprecio hacia la religión y de la libertad con la que los jóvenes y "hasta las mujeres" leían libros heréticos que atacaban dogmas fundamentales (Vázquez, 1833). Pero si para algunos la pandemia era resultado de los pecados, otros, en cambio, encontraban su causa en las condiciones antihigiénicas en que vivían y trabajaban los pobres, y buscaron modificarlas por medio del saneamiento de estos espacios.

Hubo elementos comunes a muchas epidemias y pandemias del México decimonónico: comercio paralizado, cierre temporal de fuentes de trabajo, acciones benéficas realizadas por algunos pobladores, acaparamiento y encarecimiento de productos por parte de comerciantes, escuelas clausuradas, fiestas y ceremonias canceladas, intento de aislar a los enfermos pobres en hospitales o lazaretos, realización de actividades de limpieza en espacios públicos y prohibición de ceremonias funerarias. Aunque las autoridades políticas y sanitarias, los profesionales de la salud y los pobladores tomaban contra las epidemias todas las medidas posibles, hasta finales del siglo XIX fueron impotentes ante los problemas colectivos de salud, y éstos causaron más muertos que las guerras y las catástrofes naturales.

\section{Primera década del siglo $\mathrm{XX}$ : nacimiento de la salud pública moderna}

\section{Un cambio de tuerca en el modo de enfrentar las epidemias}

Al inicio del siglo $X X$ hubo una modernización en el campo de la salud pública, la cual fue posible gracias a una combinación de factores científicos, políticos y económicos: el cambio de paradigma de la teoría miasmática a la teoría microbiológica, a partir de los descubrimientos de la bacteriología, la inmunología y la epidemiología, y su aplicación a la solución de los problemas colectivos de salud; la concentración del poder por parte del gobierno federal en materia de salud; y los intereses económicos de la burguesía exportadora de México y de empresas extranjeras. La burocracia sanitaria porfirista emprendió una campaña extraordinaria contra una epidemia de peste y hubo campañas permanentes contra la viruela, la fiebre amarilla, el paludismo, la tuberculosis y la sífilis (Carrillo, 2002b). 


\section{La campaña contra la peste}

En 1902, la peste bubónica llegó a los puertos de Ensenada y Mazatlán. Esto ocurrió durante la tercera pandemia de peste, que causó 12 millones de muertos (Arnold, 1988). Los mexicanos vivieron la epidemia con miedo, sentimiento que tomó, a veces, la forma de discriminación hacia las personas procedentes de las zonas afectadas. En esa época, la república mexicana tenía sólo dos lazaretos: uno en Veracruz y otro en Acapulco; el jefe del puerto de Acapulco objetó la posibilidad de atender a los enfermos de peste en el lazareto de La Roqueta, pero se le obligó a obedecer (AHSSA, 1903). El jefe político del territorio de Tepic expidió una proclama en la que pidió el concurso de todos los habitantes del territorio para clausurar las desembocaduras de los ríos que hacían comercio con Mazatlán y autorizó a detener en las estaciones sanitarias no sólo a los enfermos sino también a los pasajeros sanos (BECSS, 1902-1903).

Pero el temor no siempre tomó formas de irracionalidad. Fue notable la solidaridad de todo el país hacia la zona afectada por la epidemia: fue enviado ahí un total de $436,774.76$ pesos, de los que sólo 8581.90 procedían de otros lugares del mundo (Butrón y Ríos, 1916). Al parecer, los habitantes de México actuaron motivados por sentimientos humanitarios, aunque también por el instinto de conservación de su propia vida (Liceaga, 1903b), ante una enfermedad que les infundía temor. También, entre el deseo de ayudar y el temor a la enfermedad, los comerciantes y empresarios crearon una Junta de Caridad para arbitrar recursos, donar medicamentos, establecer un hospital, ayudar a identificar a quienes no estaban vacunados y aislar a enfermos y convalecientes (AHSSA, 1891-1905). Pero había una política diferencial, porque a los ricos se les dejaba permanecer en su domicilio (El Correo de la Tarde, 1902; BECSS, 1902-1903).

Sin embargo, las autoridades sanitarias no actuaron siempre a favor del poder económico. Cuando la epidemia llevaba cinco meses, la Junta de Caridad de Mazatlán pro- puso aislar a Villa Unión para poder abrir el puerto de Mazatlán al comercio. Por no contrariar a la Junta, el presidente del Consejo Superior de Salubridad estuvo de acuerdo; sin embargo, el delegado sanitario en el puerto le expuso que el aislamiento era injustificado, ya que en más de dos semanas no se había presentado un sólo caso nuevo en Villa Unión, los habitantes estaban inmunizados contra la peste y se había dado una transformación radical en la limpieza del poblado. El presidente del Consejo accedió a su petición de no aislar a ese poblado, contra el parecer de los grandes comerciantes y empresarios de Mazatlán (Butrón y Ríos, 1916).

En las comunidades afectadas, los oficiales sanitarios vacunaron a la población por voluntad o por fuerza, organizaron brigadas para buscar casa por casa a los pacientes que trataban de ocultarse, aislaron de manera rigurosa a los infectados o sospechosos de estarlo en estaciones sanitarias construidas para ese fin y se "les dejaba salir sólo si sanaban" (Liceaga, 1903a). La élite huyó tanto de la epidemia como de las rigurosas medidas sanitarias con que se le combatió; pero los indígenas, que constituían un alto porcentaje de la población mazatleca, permanecieron en el puerto ( $E$ l Correo de la Tarde, 1902b; 1902c; 1902d). Las medidas sanitarias contra la epidemia fueron aflictivas para los pobladores de Sinaloa y ahondaron las diferencias sociales y étnicas; como sucedía en otras emergencias, los pobladores intentaban escapar al orden sanitario, al tiempo que buscaban evadir la epidemia (Cueto, 1991).

Sin embargo, a diferencia de lo ocurrido en las epidemias del pasado, el Consejo Superior de Salubridad conocía al agente causal (la bacteria Yersinia pestis) y el modo de transmisión de la peste (a través de las pulgas de las ratas), y contaba con un suero curativo y dos vacunas preventivas. Armados con estas herramientas, los salubristas mexicanos organizaron una exitosa campaña para controlar la epidemia. Los pobladores, que al inicio de la emergencia sanitaria tiraban los medicamentos al río, terminaron respaldando a los representantes del Con- 
sejo de Salubridad (Carrillo, 2005): era un triunfo de la medicina moderna.

\section{Revolución, 1910-1920: hambre y abandono de las campañas sanitarias}

\section{Vuelta de epidemias}

La movilización de tropas y de población que huía de los lugares de conflicto, la pérdida de fuentes de trabajo, el abandono de las campañas de salud pública, el relajamiento de las medidas de higiene privada y el hambre, que se agregó a la desnutrición crónica del pueblo, manifestada siglos atrás, fueron las causas fundamentales de la gravedad de las endemias y epidemias durante la guerra civil (Álvarez Amézquita et al., 1960); sin embargo, esto no quiere decir que no hubiera esfuerzos para combatir los problemas de salud colectiva que hubo entonces, principalmente las epidemias de viruela, fiebre amarilla, tifus e influenza.

\section{Campaña contra el tifo: persecución a la suciedad y la miseria}

El porfirismo había comenzado y terminado con epidemias de tifus, que continuaron durante la Revolución. América Molina del Villar (2016) muestra el papel que en el desarrollo de las epidemias de tifo tuvieron la pobreza, el hambre y la guerra civil. Hacía décadas que se sabía que la enfermedad estaba asociada a la pobreza y a los lugares de suciedad y hacinamiento (Liceaga, 1906), pero no había claridad sobre su origen ni modo de transmisión (hoy se sabe que es causada por la bacteria Rickettsia prowazekii, que es generalmente transmitida por los piojos del cuerpo, que pican a un hombre sano después de haber picado a un hombre enfermo).

En 1915, el Consejo de Salubridad aceptó el papel del piojo en la transmisión del tifus y dio a la luz pública ese conocimiento, por medio de conferencias en lugares de reunión, incluyendo algunas iglesias, y la publicación de decenas de miles de ejemplares con instrucciones para combatir al piojo (Valenzuela, 1930).
En diciembre de 1915, la Secretaría de Gobernación expidió el decreto que estableció una policía especial sanitaria para combatir la epidemia en el Distrito Federal. La intención era descubrir a todos los enfermos, despiojarlos y despiojar a sus familiares; trasladar fuera de la ciudad a todos aquellos que no prestaran garantía de aislamiento en su domicilio y aislar, de modo efectivo, a los que se quedaran en la ciudad y desinfectar sus habitaciones. Doscientos médicos que desempeñaban cargos públicos participaron en la campaña (Carrillo, 2002a).

Leyendo el reporte que el jefe del Servicio Especial contra el Tifo en la capital presentó el 20 de abril de 1916, podemos imaginar el terror con que los habitantes de los barrios pobres de la ciudad de México vivieron la campaña sanitaria. Agentes sanitarios, encabezados por un jefe, recorrían la ciudad de la periferia al centro y después en sentido contrario, de modo que una casa era visitada varias veces. Los agentes iban a los dos lados de una acera, y en las casas de vecindad se concentraba todo el grupo de agentes. Descubrían, con las visitas domiciliarias, numerosos casos de tifo de los que la oficina no tenía noticia, fuera porque los enfermos no habían acudido al médico, o porque los médicos encargados de asistirlos no los habían reportado. Estos agentes hacían que se quitaran las basuras acumuladas en patios y azoteas, y quemaban colchones y almohadas viejos y sucios. Si consideraban que los animales domésticos vivían en promiscuidad con los habitantes de la casa, los sacrificaban. También visitaban y vigilaban hospitales, asilos y escuelas; comisarías y cárceles; hoteles, posadas, mesones, casas de huéspedes, dormitorios y baños públicos; templos católicos y protestantes, y cines, teatros y circos. Si lo consideraban necesario, clausuraban algunos de estos establecimientos. Los grupos de agentes impedían la entrada de personas sucias o que "parecían enfermas" a los lugares públicos, y evitaban que los mendigos se estacionaran en las puertas de las iglesias. Había más de cuarenta agentes sólo para la vigilancia en tranvías, que impedían que subieran per- 
sonas desaseadas o con bultos de ropa sucia (Pruneda, 1916).

Miles de casas fueron desinfectadas, y un centenar y medio de ellas, incineradas; decenas de miles de individuos fueron bañados y despiojados o rapados, por voluntad o por fuerza, para lo que se empleaba a agentes de la policía sanitaria, auxiliados por gendarmes; también, decenas de miles de personas fueron bajadas de los tranvías. La epidemia pudo ser combatida; sin embargo, las medidas sanitarias discriminatorias que llegaron a prohibir la entrada de los desaseados a los lugares públicos, la venta de bebidas alcohólicas, las fiestas y los velorios, así como la convivencia con animales en las casas fueron muy aflictivas para la población y hubo oposición de buena parte del público a ellas. En ocasiones, los pobladores trataron de impedir rotundamente las visitas domiciliarias, lo que motivó multas e, incluso, órdenes de aprehensión. Sin embargo, también se dio el caso de que los servicios de los agentes fueran solicitados (Pruneda, 1916; Carrillo, 2002a; Molina del Villar, 2016). A finales de 1917, la epidemia en la república había podido ser controlada, si bien permanecería como endemia. Esta política, originalmente aplicada en la ciudad de México, se extendió luego a otras entidades.

\section{La influenza: de nuevo, la incertidumbre}

La última gran emergencia sanitaria global, antes de la que hoy vivimos, se presentó hace 100 años. Se trató de la gripe o influenza de 1918-1919, de virulencia sin precedentes, que a lo largo de dos años infectó a un tercio de todos los habitantes de la tierra y mató -hoy se estima- a 50 millones de ellos. La epidemia de influenza de 1890, correspondiente a la cuarta pandemia, también se había propagado con gran rapidez en México, y se había caracterizado por la gravedad de las complicaciones (Cuenya Mateos, 2013); pero la pandemia de la segunda década del siglo $X X$ fue devastadora, pues llegó desde una Europa recién salida de la I Guerra Mundial, y cuando los mexicanos estaban cerrando, apenas, las fosas de los caídos en la guerra civil (Sánchez Rosales, 2000).

La influenza llegó al país durante la segunda de tres oleadas, en el verano de 1918, por el Golfo de México y por la frontera con los Estados Unidos, y en los dos meses siguientes había atacado a toda la república (Netzahualcoyotzi Méndez, 2003; Márquez Morfín y Molina del Villar, 2010; Cuenya Mateos, 2010). No hubo clase social, profesión, grupo de edad o sexo que lograra ponerse al abrigo de la enfermedad. Puede decirse que fue un asunto de todos, aunque, como toda pandemia, ésta sacó a la luz inequidades. Afectó, en especial, a quienes vivían congregados o hacinados, como militares, presos, internos y estudiantes; los profesionales de la salud y los servidores públicos; pero, sobre todo, a los pobres y, algo traumático para la sociedad: los adultos jóvenes. Lo mismo puede decirse de las personas con enfermedades crónicas, como la tuberculosis. La gente caía muerta en la calle y fueron muchos los que tuvieron que ser enterrados sin ataúd (Leopoldo Flores citado por CarriIlo, 2002a).

Lo anterior se debía, en parte, a los límites del conocimiento científico, ya que no había contra el padecimiento una vacuna ni un tratamiento específico y el agente causal de la influenza (el virus de la influenza) no sería identificado hasta 1930. Los médicos sabían, eso sí, que la transmisión de la enfermedad se da por secreción respiratoria y por objetos contaminados. Por ello, la profilaxis consistió básicamente en aislar a los enfermos; las autoridades sanitarias cerraron las escuelas y los templos religiosos y prohibieron las reuniones masivas (Carrillo, 2002a).

De acuerdo con Márquez Morfín y Molina del Villar (2010), en el Distrito Federal se ordenó que los enfermos de influenza fueran recluidos en el Hospital General o en los consultorios de beneficencia y, por miedo a la exclusión, los "menesterosos" se escondían en sus domicilios sin dar aviso a las autoridades, por lo que se ordenó que los agentes especiales del Consejo Superior de Salubridad recorrieran las vecindades de 
los barrios para indagar si había enfermos de gripe y hospitalizarlos por la fuerza. Sin embargo, muy pronto los hospitales se vieron saturados e incapacitados para atender a todos los enfermos llevados por los comisarios de policía.

La pandemia tuvo efectos profundos en la economía por la alta mortalidad entre personas en edad reproductiva y, hasta entonces, económicamente activas; el cierre de empresas e instituciones públicas y la clausura de actividades productivas. Algunas minas y fundiciones tuvieron que parar, a causa de que 2000 mineros estaban enfermos de influenza, lo que provocó escasez de carbón y esto, a su vez, la detención de los ferrocarriles (Molina del Villar, 2021).

\section{México contemporáneo: logros y retos}

\section{Epidemias y campañas}

Desde el fin de la Revolución, todas las enfermedades que en el pasado se habían presentado como endemias, epidemias o pandemias volvieron a afectar a la población mexicana, pero también fueron reorganizadas las campañas sanitarias; por ejemplo, contra la fiebre amarilla, de la que hubo nuevos casos desde los años de la lucha armada, o contra una nueva epidemia de peste, procedente de Nueva Orléans, en 1920; también lo fueron las campañas contra la viruela, la tuberculosis y las entonces llamadas enfermedades venéreas. Poco a poco se organizó, igualmente, el combate a la anquilostomiasis, la lepra, el mal de pinto, el paludismo, la oncocercosis, el cáncer y otras enfermedades (Carrillo, 2002a).

\section{Viruela y poliomielitis}

El logro más importante contra las enfermedades epidémicas fue la eliminación de la viruela que, de hecho, es la única enfermedad que ha sido erradicada del planeta. La Organización Mundial de la Salud declaró que la enfermedad había sido eliminada de México el 16 de junio de 1952, después de un año sin casos. Se puso así fin a más de cuatro siglos de epidemias recurrentes e incapacitantes (Cramaussel y Carbajal, 2010) y a 147 años de esfuerzos por vacunar a toda la población (Aguirre Bolaños, 2015; Agostoni, 2016).

Lo anterior dio a la medicina un sentimiento de triunfo que duró poco, pues casi al mismo tiempo el país tuvo que hacer frente a la poliomielitis, que fue realmente otra pandemia. La enfermedad era denominada en el pasado "parálisis infantil epidémica"; el sólo nombre explica la angustia que experimentaban ante ella los padres del mundo. La poliomielitis era muy contagiosa, podía causar -además de la muerte por asfixiaparálisis irreversible y atacaba sobre todo a los niños, en particular a los muy pequeños. El grupo de edad más afectado era el de 0 a 3 años, con casi 95\% de los casos (Fujigaki Lechuga y González Galván, 1982). En los años sesenta, prácticamente no había en México un salón de clase en que no hubiera un niño o niña con secuelas de poliomielitis.

No había claridad sobre el modo en que se transmitía la polio y tampoco había, ni hay, cura. Uno de los esfuerzos se daba en la rehabilitacón de quienes la habían padecido. El Hospital Infantil (luego Instituto Nacional de Pediatría), el Hospital Militar, el Hospital (luego Instituto Nacional) de Rehabilitación, el Instituto Mexicano del Seguro Social, la Central Pedagógica Infantil y la Clínica Primavera de Ortopedia, entre otras instituciones -financiadas tanto por el Estado como por particulares-, atendieron a quienes habían padecido polio. Pero se buscaba el modo de prevenirla.

Desde 1956 se dispuso de la vacuna inyectada, desarrollada por Jonas Salk, y, a partir de 1961, de la vacuna oral, desarrollada por Albert Sabin; éstas fueron motivo de esperanza, aunque a veces también de angustia, por sus efectos adversos o desconocidos. México las produjo y la eliminación de la enfermedad se lograría, con la vacunación, en 1990. Sin embargo, antes de que las vacunas llegaran, hubo otros intentos, poco conocidos hasta ahora, para evitar que la enfermedad se desarrollara, como el empleo de globulina gamma.

Investigadores mexicanos establecieron, 
desde 1949, la existencia de anticuerpos a los virus de polio en sangre de jóvenes y adultos mexicanos, por lo que supusieron que habían sido infectados en el pasado, sin presentar manifestaciones. Más tarde, William Hammon, de la Universidad de Pittsburgh, purificó la globulina gamma, un componente del plasma sanguíneo de sobrevivientes de la polio, y señaló que éste podía conferir una protección temporal contra la enfermedad (Rinaldo, 2005).

El Comité Nacional de Lucha contra la Poliomielitis buscó proteger con ella a los niños mexicanos y logró un amplio apoyo por parte de los profesionales de la salud, instituciones oficiales (la Secretaría de Educación Pública y muchos hospitales públicos), empresas privadas (laboratorios y hospitales, y las cámaras de Radio y Televisión), partidos políticos y sindicatos. Fue notoria la participación del público en general, que donó voluntariamente su sangre con el deseo de ayudar a la niñez mexicana. La colecta estaba programada en las principales ciudades de la república, pero el Comité se vio obligado a extenderla a otras, ante la presión de sus pobladores: Guadalajara, Monterrey, Puebla, Cuernavaca, Chilpancingo, Guanajuato, León, Celaya, Pachuca, Tula, Hidalgo, Toluca y Tlalnepantla. Además, se formaron brigadas para atender la creciente demanda de núcleos humanos que insistían en donar sangre en sus centros de trabajo o estudio. Al final, se obtuvieron 6599 litros de sangre de 25,737 voluntarios, con los que fue posible elaborar cerca de 100,000 dosis individuales de globulina gamma humana, que se aplicaron a niños de entre 6 meses y 5 años, de todas las clases sociales.

Los organizadores de la campaña reportaron haber encontrado una influencia importante de la gamma globulina en la disminución de la intensidad de epidemias de parálisis infantil, cuando se aplicaba oportuna y colectivamente al mayor número de niños del grupo de edad más susceptible (es decir, el de menores de cinco años); pero, proporcionaba sólo una breve protección (su acción era de seis semanas), por lo que esta campaña no continuó. Sin embargo, Ila- ma la atención cómo se desbordó el pueblo mexicano para apoyar la campaña. A los donadores se les decía que al dar su sangre ganaban una prioridad para sus hijos si las circunstancias epidemiológicas obligaban a la aplicación en su zona, pero muchos no aceptaron la constancia de su donación, que querían conservar como altruista y anónima (Calderón et al., 1953).

\section{3-2021: viejas y nuevas enfermedades}

\section{De las enfermedades infecciosas a las enfermedades crónicas}

Como en el resto del mundo, aunque en tiempos diferentes, en México se dio una transición demográfica, caracterizada por menor mortalidad infantil y mayor esperanza de vida. También, una transición epidemiológica; si en la primera mitad del siglo XX las enfermedades infecciosas -pneumonía e influenza, diarrea y enteritis, paludismo, viruela, sarampión, tosferina y difteria- habían sido las principales causas de morbilidad y mortalidad, en la segunda mitad del siglo $X X$, las principales causas de muerte fueron enfermedades no transmisibles, como las enfermedades del corazón, la diabetes y los tumores malignos, que tienen que ver, por un lado, con el aumento de la esperanza de vida de la población mexicana $y$, por otro, con la vida sedentaria, la mala alimentación y el estrés. En países como México, y sobre todo en las poblaciones rurales, hay una situación de doble carga, porque al lado de las crónico-degenerativas, se siguen presentando enfermedades infecciosas y contagiosas.

\section{Nuevos tiempos de pandemia}

Roy Porter (2006) señaló que la autoconfianza de la profesión médica había sido vulnerada en varias ocasiones durante el siglo XX; por ejemplo, durante la pandemia de influenza de 1918-1919 y en el encuentro de la medicina moderna con la poliomielitis. Hoy podríamos agregar el surgimiento de las en- 
fermedades emergentes, las cuales se han presentado en las últimas décadas. Se trata de enfermedades transmisibles nuevas, que tienen que ver con la huella del hombre sobre el planeta: deforestación, agroindustria, minería y cría industrial de animales. Patógenos antes desconocidos para el hombre han emergido y han hecho que nuevas epidemias cobren forma (Green, 2020). Un ejemplo es el del Sida, cuyo origen se dio, al parecer, por contacto del ser humano con chimpancés de Camerún, África; a su llegada a México, en 1983, esta enfermedad hizo resurgir explicaciones religiosas, que trataban de ligar a las epidemias con supuestos pecados, además de motivar la búsqueda de chivos expiatorios, esta vez entre la población gay. Se ejercieron contra los enfermos muchas formas de discriminación (García Murcia et al., 2012), y es que siempre ha sido más fácil señalar culpables y discriminarlos, que indagar en las verdaderas causas de las epidemias.

\section{La pandemia de la enfermedad del coronavirus}

La COVID-19 es otra de estas enfermedades emergentes. Dicen Charters y Mckay (2020) que, por ausencia de experiencia vivida en pandemias, se ha buscado a la historia y los historiadores. La actual emergencia sanitaria, que se presenta en la era digital, es diferente de cualquiera que la humanidad haya vivido antes: ya sea por la rapidez con que se transmite la información... y la desinformación, malintencionada o no, o porque las actividades escolares y algunos trabajos han podido realizarse desde el hogar, con la posibilidad de conservar el salario, pero también con la consecuente violación de la privacidad.

Aunque en el pasado hubo cuarentenas y aislamiento forzado, el confinamiento simultáneo que desde el año 2020 se ha dado por la COVID-19 no tiene precedentes en la historia del mundo: ahora tenemos megalópolis desiertas. Esta política sanitaria tiene la finalidad de salvar vidas; pero ha provocado, como efectos colaterales, una agudi- zación de la crisis económica mundial, que -en opinión de algunos- es más devastadora que la propia epidemia; así como el incremento de la violencia al interior del hogar, la depresión, las adicciones y los suicidios de jóvenes y niños.

Hay también similitudes con las pandemias del pasado. Se repiten el temor generalizado provocado por el número de enfermos y el alto porcentaje de los fallecidos entre ellos; el trastocamiento profundo de las actividades económicas, políticas, sociales y culturales y, en general, de la vida cotidiana; la afectación de todas las clases sociales, aunque de manera desigual y, quizá por ello, la polarización política y la agudización de conflictos previamente existentes en la sociedad. También hay semejanzas en el temor al forastero y el cierre de fronteras; la soledad de los moribundos y la imposibilidad de cumplir con los ritos sociales o religiosos para los difuntos; los hospitales desbordados; los debates sobre si los servicios de salud, incluyendo las vacunas, son mercancías privadas o bienes públicos; la exigencia de medidas coercitivas por parte de algunos y la resistencia ante tales medidas por parte de otros, así como el debate que esta oposición despierta entre el respeto a las libertades individuales y el bienestar común (Carrillo, 2020).

Una semejanza más es la falta de certeza científica y las dudas ante el futuro. La medicina tiene aún muchas incertidumbres; por ello, recurre a la desinfección, el lavado de manos y el uso de máscaras, que -como señaló Henry Sigerist (1987)- ya se habían usado en la pandemia de influenza de 1918-1919 e incluso en la segunda pandemia de peste de la Edad Media, conocida como muerte negra. Quizá también por esas incertezas, algunos han vuelto a la búsqueda de culpables, cuyas máximas muestras de irracionalidad han sido los ataques a quienes se ocupan del cuidado de la salud. Se repiten, por último, la entrega hasta el heroísmo de muchos profesionales de la salud y el intento de evadir responsabilidades de otros; así como las conductas extremas que oscilan entre el intento de enriquecerse a costa de la tragedia y la solidaridad-fraternidad-sororidad. 
Dice el historiador Frank Snowden (citado en Alconada Mon, 2020): "Las pandemias son como mirarse al espejo de la humanidad, y puedo decir que no todo es bello [...] tenemos un lado oscuro. Pero también un lado brillante [...] hay héroes en esta historia". Dice también que las pandemias nos plantean preguntas de vida o muerte y nuestra actitud hacia ambas, además de que tocan las fibras íntimas de la naturaleza humana.

\section{Reflexiones finales}

En los 200 años transcurridos desde el nacimiento de la nación mexicana, el país ha sufrido transformaciones políticas, económicas y sociales, que se han reflejado en su perfil epidemiológico. En este largo periodo, la población mexicana ha estado expuesta de manera constante a endemias, epidemias y pandemias. Ellas han atacado repentinamente a grandes grupos, y su mayor o menor huella ha estado dada, en primer lugar, por su intensidad, medida en términos del número de enfermos y muertos que han causado; y en segundo lugar, por el dislocamiento social que han provocado al afectar la vida de grupos enteros, sobre todo cuando las víctimas han sido jóvenes o niños. Encontramos su resonancia en la actual emergencia sanitaria.

La primera vez que una enfermedad aparece, causa mayor sorpresa; esto ha sucedido con los primeros casos de cólera, peste, poliomielitis, Sida, COVID-19. Se ha tratado de hechos dramáticos, repentinos, que han sido causa de elevadas tasas de enfermedad y de muerte y que han impactado el sentir colectivo, por lo que han demandado la respuesta de toda la sociedad. A principios del siglo XX, debido a los avances de la medicina, los mexicanos comenzaron a vivir las enfermedades epidémicas ya no como desgracias -cuyo desenlace afortunado o funesto dependía de la buena o mala fortuna o, incluso, de la voluntad divina-, sino como alteraciones del curso normal de la vida que tenían causas, y a entender que combatiendo éstas era posible atajar aquéllas. Sin embargo, después de eso, se han presentado epidemias que han vuelto a significar un reto para las ciencias médicas.

La intención de este artículo ha sido contribuir a mirar la enfermedad del coronavirus en perspectiva histórica y también a estudiar las epidemias del pasado con nuestras preocupaciones del presente. Los problemas colectivos de salud han sido tributarios de las condiciones materiales y culturales que han imperado entre 1821 y 2021, y a su vez han tenido un alto impacto en la economía, la política, la ciencia y la vida social. Por ello, son componente fundamental de la historia general del país. En el pasado, las epidemias cesaron finalmente y la población mexicana fue capaz de superar las muertes colectivas y reinventar sus sociedades. Sin duda, en el futuro tendrá la posibilidad de mostrar, de nuevo, su capacidad de resiliencia.

\section{Fuentes de consulta}

Agostoni, Claudia (2016), Médicos, campañas y vacunas. La viruela y la cultura de su prevención en México, 1870- 1952, México, Universidad Nacional Autónoma de México / Instituto de Investigaciones Dr. José María Luis Mora.

Aguirre Bolaños, Nydia (2015), "La alineación de los planetas: erradicación de la viruela en México: 1941-1977", tesis de licenciatura, UNAM, Ciudad de México.

AHSSA (Archivo Histórico de la Secretaría de Salud) (1891-1905), Salubridad pública, Expedientes de personal, caja 42, exp. 1, f. 213-b.

AHSSA (Archivo Histórico de la Secretaría de Salud) (1903), Sesión del 28 de enero, Salubridad pública, Presidencia, actas de sesiones, caja 12, exp. 3, 299 ff.

Alconada Mon, Hugo (2020), "Frank Snowden: 'Las epidemias son como mirarse al espejo de la humanidad, y puedo decir que no todo es bello'”, La Nación, 29 de marzo, Buenos Aires, La Nación, El mundo, <https://cutt.ly/Uv7F5Yh>, 30 de marzo de 2020. 
Álvarez Amézquita, José; Bustamante, Miguel E.; López Picazos, Antonio y Fernández del Castillo, Francisco (1960), Historia de la salubridad y de la asistencia en México, México, Secretaría de Salubridad y Asistencia. Cuatro volúmenes.

Armendáriz, Eduardo (1894), "Breves apuntes sobre la última epidemia de tifo en Guanajuato", Anales del Instituto Médico Nacional, I, México, Instituto Médico Nacional, pp. 141-154.

Arnold, David (1988), "Introduction: Disease, Medicine and Empire", en David Arnold (ed.), Imperial Medicine and Indigenous Societies, Gran Bretaña, Manchester University Press, pp. 1-26.

"Bando del 15 de marzo de 1833 dado por el general José Joaquín de Herrera, gobernador del Distrito Federal", Biblioteca de la Antigua Escuela de Medicina / Facultad de Medicina, UNAM.

BECSS (Boletín Extraordinario del Consejo Superior de Salubridad) (1902-1903), Peste, núm. 1, diciembre-enero.

Briggs, Asa (1961), "Cholera and society in the nineteenth century", Past and Present, XIX (1), s/I, Oxford University Press, pp. 76-96.

Bustamante, Miguel E. (1982), "La situación epidemiológica de México en el siglo XIX", en Enrique Florescano y Elsa Malvido (comps.), Ensayos sobre la historia de las epidemias en México, vol. II, México, Instituto Mexicano del Seguro Social, pp. 435-476.

Bustamante, Miguel E. (1977), "Consecuencias médico-sociales de la viruela y de su erradicación", Gaceta Médica de México, México, Academia Nacional de Medicina, 113, pp. 564-73.

Bustamante, Miguel E. (1958), La fiebre amarilla en México y su origen en América, México, Secretaría de Salubridad y Asistencia.

Butrón y Ríos, Antonio (1916), Epidemiología. Datos históricos sobre la peste bubóni- ca de 1902 a 1903 en el estado de Sinaloa, México, México, Andrés Botas.

Calderón, Carlos; Ornelas, Adán; Ponce de León, Alfonso y Núñez Rivera, Alberto (1953), "Resultados de la globulina gamma como preventivo de la polio en México", en Secretaría de Salubridad y Asistencia, Simposio de poliomielitis, México, SSA, pp. 29-35.

Carrillo, Ana María (2020), "Históricamente, las pandemias han acentuado brechas entre países y clases sociales, pero son oportunidades para plantear políticas públicas de largo plazo", Claves. Revista de Historia, 6 (10), Instituto de Ciencias Históricas de la Facultad de Humanidades y Ciencias de la Educación, Universidad de la República, Uruguay, pp. 327-333, <https://bit.ly/3gbPUcu>, doi: $10.25032 /$ crh.v6i10.18

Carrillo, Ana María (2005), "¿Estado de peste o estado de sitio?: Sinaloa y Baja California, 1902-1903", Historia Mexicana, LIV (4), México, El Colegio de México, pp. 1049-1103, <https://cutt.ly/tv7GUFr>, 15 de febrero de 2021.

Carrillo, Ana María (2002a), "Surgimiento y desarrollo de la participación federal en los servicios de salud", en Guillermo Fajardo, Ana María Carrillo y Rolando Neri Vela, Perspectiva histórica de la atención a la salud, México, Organización Panamericana de la Salud / Universidad Nacional Autónoma de México / Sociedad Mexicana de Historia y Filosofía de la Medicina, pp. 17-64, <https://cutt.ly/cv7GB8V>, 12 de enero de 2021.

Carrillo, Ana María (2002b), "Economía, política y salud pública en el México porfiriano (1876-1910)", História, Ciência, Saúde. Manguinhos, IX-suplemento, Río de Janerio, Fundación Oswaldo Cruz, pp. 67-87, doi: https://doi.org/10.1590/ S0104-59702002000400004

Chambers, J. S. (1938), The Conquest of Cholera: America's Greatest Scourge, Nueva York, The Mcmillan Co. 
Charters, Erica y Mckay, Richard A. (2020), "The History of Science and Medicine in the context of COVID-19", Centaurus, LXII, s/I, European Society for the History of Science, pp. 223-233. doi: https://doi.org/10.1111/1600-0498.12311

Chevalier, Louis (2018, $1^{a}$ 1958), Le choléra: la première epidémie du XIXe siècle, Lyon, Universidad de Lyon.

Contreras Sánchez, Alicia y Alcalá Ferráez, Carlos (eds.) (2014), Cólera y población, 1833-1854. Estudios sobre México y Cuba, Zamora, El Colegio de Michoacán.

Cook, Sherburne F. y Borah, Woodrow (1977), Ensayos de población: México y el Caribe. Ciudad de México, Siglo XXI.

Cooper, Donald B. (1980), Las epidemias en la ciudad de México, 1761-1813, México, Instituto Mexicano del Seguro Social.

Cramaussel, Chantal y Carbajal, David (eds.) (2010), El impacto demográfico de la viruela de la época colonial al siglo XX. Estudios de larga duración. México, El Colegio de Michoacán. Tres volúmenes.

Cuenya Mateos, Miguel Ángel (2013), "Reflexiones en torno a una pandemia olvidada. La influenza de 1890 en la ciudad de Puebla", en Miguel Ángel Cuenya y Rosalina Estrada Urroz (eds.), Enfermedades, epidemias, higiene y control social. Nuevas miradas desde América Latina, México, Benemérita Universidad Autónoma de Puebla.

Cuenya Mateos, Miguel Ángel (2010), "Reflexiones en torno a la pandemia de influenza de 1918: el caso de la ciudad de Puebla", Desacatos. Revista de Ciencias Sociales, (32), México, Centro de Investigaciones y Estudios Superiores en Antropología Social, pp. 145-158.

Cuenya Mateos, Miguel Ángel; Malvido, Elsa; Lugo, Concepción; Carrillo, Ana María y Oliver Sánchez, Lilia (1992), El cólera de 1833: una nueva patología en México. Causas y efectos, México, Instituto Nacional de Antropología e Historia.
El Correo de la Tarde (1902a), s/t, 19 de diciembre, Mazatlán, p. 1.

El Correo de la Tarde (1902b), s/t, 27 de diciembre, Mazatlán, p. 1.

El Correo de la Tarde (1902c), s/t, 29 de diciembre, Mazatlán, p. 1.

El Correo de la Tarde (1902d), s/t, 31 de diciembre, Mazatlán, p. 1.

Florescano, Enrique y Malvido, Elsa (comps.) (1982), Ensayos sobre la historia de las epidemias en México, México, Instituto Mexicano del Seguro Social. Dos volúmenes.

Fujigaki Lechuga, Augusto y González Galván, Alfonso (1982), "Epidemias conocidas en México durante el siglo XX", en Enrique Florescano y Elsa Malvido (comps.), Ensayos sobre la historia de las epidemias en México, vol. II, México, Instituto Mexicano del Seguro Social, pp. 699-719.

Gámez, Moisés (1999), "Salud pública: la fiebre del orden. Interpretación sobre la política sanitaria en San Luis Potosí a fines del XIX”, Vetas, I, San Luis Potosí, El Colegio de San Luis, pp. 95-109.

González Flores, José Gustavo (coord.), (2017), Epidemias de matlazahuatl, tabardillo y tifo en Nueva España y México. Sobremortabilidad, Saltillo, Universidad Autónoma de Coahulia.

González Navarro, Moisés (1970, 1a 1957), "La vida social", en Daniel Cosío Villegas (ed.), Historia moderna de México, v. III, México, Hermes.

Gostin, Lawrence O.; Daniel, Lucey y Phelan, Alexandra (2014), "The Ebola Pandemic. A Global Health Emergency", JAMA, 312 (11), s/l, pp. 1095-1096, doi:10.1001/jama.2014.11176

Green, Monica H. (2020), "Emerging diseases, re-emerging histories", Centaurus, LXII, s/I, European Society for the History of Science, pp. 234-247, doi: https://doi.org/10.1111/1600-0498.12306 
Hernández Rodríguez, Rosaura (1962), “Epidemias y calamidades en el México prehispánico", Anuario de Historia, II, México, UNAM, pp. 21-35.

Hutchinson, C. A. (1984), "El cólera de 1833: el día del juicio en México", en Páginas de los Trabajadores del Estado, (3), México, ISSSTE, pp. 14-26.

Liceaga, Eduardo (1906), "Algunos datos estadísticos relativos al tifo que reina endémicamente en la capital, y a sus exacerbaciones epidémicas", Gaceta Médica de México, VI, México, Academia Nacional de Medicina, pp. 287-93.

Liceaga, Eduardo (1903a), "La peste bubónica en Mazatlán", Boletín del Consejo Superior de Salubridad, III, pp. 287-93.

Liceaga, Eduardo (1903b), "Informe del doctor Liceaga sobre los trabajos Ilevados a cabo para extinguir en la República la epidemia de peste bubónica", Gaceta Médica de México, XX, México, Academia Nacional de Medicina, pp. 296-298.

Littman, Robert J. y Littman, M. L. (1969), "The Athenian Plague: Smallpox", Transactions and Proceedings of the American Philological Association, 100, Johns Hopkins University, pp. 261-75, doi: https://doi.org/10.2307/2935915

Márquez Morfín, Lourdes (1994), La desigualdad ante la muerte en la ciudad de México, México, Siglo XXI.

Márquez Morfín, Lourdes y Molina del Villar, América (2010), "El otoño de 1918: las repercusiones de la pandemia de gripe en la ciudad de México", Desacatos. Revista de Ciencias Sociales, (32), México, Centro de Investigaciones y Estudios Superiores en Antropología Social, pp. 121-144.

McCaa, Robert (1995), "Spanish and Nahuatl Views on Smallpox and the Demographic Catastrophe in Mexico", Journal of Interdisciplinary History, 25 (3), The MIT Press, pp. 397-431, doi: https://doi. org/10.2307/205693
Molina del Villar, América (2021), "El Norte de México entre pandemias. La influenza de 1918", Desacatos. Revista de Ciencias Sociales, (65), México, Centro de Investigaciones y Estudios Superiores en Antropología Social, pp. 14-33.

Molina del Villar, América (2016), Guerra, tifo y cerco sanitario en la ciudad de México, 1911-1917, México, Centro de Investigaciones y Estudios Superiores en Antropología Social.

Molina del Villar, América (1996). Por voluntad divina: escasez, epidemias y otras calamidades en la ciudad de México, 1700-1762, México, Centro de Investigaciones y Estudios Superiores en Antropología Social.

Molina del Villar, América; Márquez Morfín, Lourdes y Pardo Hernández, Claudia Patricia (eds.) (2013), El miedo a morir. Endemias, epidemias y pandemias en México: análisis de larga duración. México, CIESAS / Instituto Mora / BUAP / CONACYT, pp. 19-49.

García Murcia, Miguel; Andrade Briceño, Magdalena; Maldonado Arroyo, Ricardo y Morales Escobar, Claudia (2012), Memoria de la lucha contra el VIH en México. Los primeros años, México, Historiadores de las Ciencias y las Humanidades / Conapred.

Netzahualcoyotzi Méndez, Marciano (2003), La epidemia de gripe de 1918 en Tlaxcala, México, Universidad Autónoma de Tlaxcala.

Peset, Mariano y Peset, José Luis (1972), Muerte en España (política y sociedad entre la peste y el cólera), Madrid, Hora $\mathrm{H}$.

Porter, Roy (2006), The Cambrigde History of Medicine, Cambridge, Cambridge University Press.

Pruneda, Alfonso (1916), "Informe sobre los trabajos efectuados por el Servicio Especial contra el Tifo, desde que fue establecido hasta el 20 de abril de 1916 en que dejó de funcionar" [mecanoescrito], Archivo Particular Alfonso Pruneda, sin clasificar, $18 \mathrm{p}$. 
Rinaldo, Charles R. (2005), "Passive Immunization Against Poliomyelitis. The Hammon Gamma Globulin Field Trials, 1951-1953", American Journal of Public Health, 95 (5), Washington, American Public Health Association, doi:10.2105/ AJPH.2004.040790

Ryan, Edward T. (2011), "The Cholera Pandemic, Still with Us after Half a Century: Time to Rethink", Plos Neglected Tropical Diseases, 5 (1), California, PLOS, pp. 1-2, doi: https://doi.org/10.1371/journal. pntd.0001003

Sánchez Rosales, Gabino (2000), "La epidemia de influenza española de 1918; aproximación a una historia compartida México-Estados Unidos", Boletín Mexicano de Historia y Filosofía de la Medicina, 3 (2), s/I, Sociedad Mexicana de Historia y Filosofía de la Medicina, pp. 17-25.

Serrano, Carlos y Castillo, Noemí (1984), "Los primeros pobladores. Salud y enfermedad en la etapa Lítica", en Alfredo López Austin y Carlos Viesca Treviño (eds.) Historia general de la Medicina en México, vol. 1, México, UNAM / Facultad de Medicina / Academia Nacional de Medicina, pp. 41-48.

Sigerist, Henry (1987, 1a 1943), Civilización y enfermedad, México, Instituto Nacional de Salud Pública / Fondo de Cultura Económica.

UNAIDS (2021), "Global HIV \& AIDS statistics. 2020 fact sheet", s/I, ONUSIDA, <https://cutt.ly/ov7HoT2>, 30 de marzo de 2021.

Valenzuela, Francisco (1930), "Las campañas contra el tifo, del año 1912 a 1917", Salubridad. Órgano del Departamento de Salubridad Pública, I (1), México, Secretaría de Salubridad y Asistencia, pp. 28-37.

Vázquez, Francisco Pablo (1833), Pastoral que el illmo. Sr. Dr. D. Francisco Pablo Vázquez, obispo de la Puebla de los Ángeles, dirige a sus diocesanos con motivo de la peste que amenaza, 8 de junio, Puebla, Imprenta del Hospital de San Pedro.
Worldometer (2021), "COVID-19 Coronavirus Pandemic", s/l, Worldometer, <https:// cutt.ly/Dv7Hklo>, 9 de abril de 2021.

Recibido: 2 de marzo de 2021. Reenviado: 2 de marzo de 2021. Aceptado: 6 de abril de 2021.

\section{Ana María Carrillo}

Doctora en Historia por la Facultad de Filosofía y Letras de la UNAM. Profesora titular del Departamento de Salud Pública de la Facultad de Medicina de la UNAM. Miembro del Sistema Nacional de Investigadores, nivel II. Se especializa en historia de las epidemias, la salud pública y las profesiones sanitarias. Sus publicaciones más recientes son: "Vaccine production, national security anxieties and the unstable state in nineteenth and twentieth century Mexico", en Christine Holmberg, Stuart Blume y Paul Greenough (eds.), The Politics of vaccination. A global History, Manchester, Manchester University Press (Series: Social Histories of Medicine), pp. 121-147 (2017); "Saúde e educação: a formaçao profissional entre principios do século XX e do XXI", en Liane Maria Bertucci, André Mota y Lilia Blima Schraiber (orgs.), Saúde e educação, um encontro plural, Río de Janeiro, Fundación Oswaldo Cruz, pp. 19-33 (2017); y “¿Qué puede decirnos la historia de las epidemias y la salud pública sobre la vida cotidiana?", en Pilar Gonzalbo (coord.), La historia y lo cotidiano, México, El Colegio de México, pp. 291325 (2019). ORCID 0000-0002-7981-2065. 
